Review

\title{
Cluster as an Innovational and Organizational Form of State Regulation of Business
}

\author{
Alexandr Dzhindzholia, Elena Popkova and Larisa Shakhovskaya \\ Department of International Economics and Economic Theory, Volgograd State Technical University, Volgograd, Russia
}

\author{
Article history \\ Received: 27-07-2015 \\ Revised: 07-11-2015 \\ Accepted: 09-11-2015 \\ Corresponding Author: \\ Elena Popkova \\ Department of International \\ Economics and Economic \\ Theory, Volgograd State \\ Technical University, \\ Volgograd, Russia \\ Email: elenapopkova@yahoo.com
}

\begin{abstract}
This article studies state regulation of business determines and analyzes its economic, legal and organizational forms. The authors offer and substantiate the hypothesis that cluster is an innovational and organizational form of state regulation. Peculiarities and advantages of cluster for development of modern business are determined.
\end{abstract}

Keywords: Cluster, Innovational and Organizational form of State Regulation, Development of Business

\section{Introduction}

International experience of management of innovational and scientific and technical development of business shows that the state level includes the objective process of synthesis of scientific, economic and social policy, aimed at creation of various forms of cluster entities, for the purpose of creation and support for business environment in Russia which would facilitate creation and active use of novelties in the practice of business.

At that, competitiveness of modern economy, oriented at knowledge, depends not only on creation and generation of knowledge, discoveries and technical achievements but on organizational changes which facilitate the commercialization of the results of scientific and technical developments, as well as marketing innovations.

This leads to the necessity for the search for innovational forms of state regulation of business which facilitate the synthesis of new knowledge and successful commercialization of innovations. This research offers the hypothesis that creation of clusters (clustering of economy) is such innovational form of state regulation. The purpose of this research is verification of the offered hypothesis about the necessity for creation of such innovational and organizational form of state regulation of business development as cluster, determination of its peculiarities and advantages, as compared to other managerial means, methods and tools.

\section{Materials and Methods}

State regulation of business is primarily activities of state through its bodies, aimed at implementation of state economic policy with the use of special methods (means, forms). State regulation is conducted as to business activities on the whole and as to its particular types (Popkova and Tinyakova, 2013a).

The aims of state regulation of business suppose solving a range of specific tasks, aimed at implementation of functions of the state in the sphere of economy. The main methods of state regulation of activities of subjects of small and medium business are economic, organizational and legal regulation. Besides, the necessary methods of state regulation are state support and protection of the subjects of small and medium business (Popkova and Tinyakova, 2013b).

Besides, it is necessary to distinguish state control over the fulfillment of requirements of the law by the subjects of small and medium business. Means, methods and forms of state regulation of business are classified according to the level of usage of some or other tools of influence. Thus, it is possible to distinguish state regulation at federal level and at the level of the subject of the Federation (Popkova et al., 2013).

The economic form of state regulation is, primarily, tax regulation. The influence of the system of taxation on entrepreneurial activities can stimulate. Slow down, or stop its particular types. Taxes are the main source of formation of budgets of all levels, through which the implementation of socio-economic functions of any economic subject and state on the whole is conducted.

Economic forms include also custom and currency regulation. Besides, one of the most important forms of economic state regulation is forecasting and programming of socio-economic development of business. 
Regional taxes are taxes determined by the Fiscal Commission of the Russian Federation and the laws on taxes of the RF subjects; they are mandatory in the territories of the corresponding subjects of the Russian Federation. Regional taxes include:

- Tax on organizations' property

- Tax on gambling business

- Transport tax

Entrepreneurs can use the general system of taxation. In this case, they have to pay all taxes, according to which they are acknowledged as taxpayers; still, regarding some categories of entrepreneurs, the Fiscal Commission of the RF determines special tax regimes which include:

- $\quad$ Simplified taxation system

- Taxation system in the form of single tax on imputed income for certain activities

- Patent system of taxation

- $\quad$ Single agricultural tax

Single agricultural tax is set and implemented by the Tax Code of the RF. The taxation system in the form of single tax on imputed income for certain activities is set by the Tax Code of the RF and implemented by normative legal acts of representative bodies of municipal areas and city districts.

As for simplified and patent taxation systems, the bodies of executive power of the RF have the right, granted by the laws of the RF subjects, to set on the territory of the jurisdictional subject the differentiated tax rates on the simplified taxation system in the range of $5-15 \%$, depending on the categories of taxpayers, as well as to set the values of potentially possible yearly income of individual entrepreneurs as to the types of business activities, to which the patent taxation system is applied.

According to the Russian statistical tax data, the share of the quantity of given patents in the total quantity of individual entrepreneurs, which are registered for tax purposes, is less than $1 \%$, which shows low activity of individual entrepreneurs' purchasing patents.

The results of the analysis of usage of patent system showed that the main factor which negatively influences the activity of the usage of this system of individual entrepreneurs was the impossibility for differentiating the size of potentially possible yearly income depending on the peculiarities of entrepreneurial activities. For example, location, socio-economic specifics, etc., while the taxation system in the form of single tax on imputed income supposes such differentiation, thus being more profitable for businessmen.

At the federal level, the list of taxpayers that use the patent system of taxation will include the self-employed citizens-individuals which do not have any employees. Such self-employed citizens will be registered in tax administration as taxpayers of the patent system of taxation and as individual entrepreneurs on the basis of application for a patent and removed from the register as taxpayers after expiration of the patent.

According to Article 5 of the Federal Law dated July 24, 2009, No. 212-FZ“On Insurance Premiums to the Pension Fund, Social Insurance Fund, Mandatory Medical Insurance Fund and Territorial Funds of Obligatory Insurance of the Russian Federation", individual entrepreneurs who do not conduct any payments or other rewards to individuals shall perform the payment of insurance premiums of fixes size.

Up to January 1, 2013, the fixed size of insurance premium for obligatory insurance was calculated on the basis of 1 minimum monthly wage. According to the Federal Law dated December 3, 2012, No. 243FZ"On Amending Certain Legislative Acts of the Russian Federation in Connection to Issues of Mandatory pension Insurance", beginning from January 1, 2013, the fixed size of insurance premium for mandatory pension insurance was increased by 2 times, to RUB $32,479.2$ (calculation on the basis of 2 minimum monthly wages).

This decision resulted in significant reduction of the number of registered individual entrepreneurs in 2013. The number of Russian individual entrepreneurs decreased by 120,000 and constituted 590,100 in 2013. In 2014, there was stabilization and slightly positive dynamics of growth of the number of individual entrepreneurs-their number, as of October 1,2014 , constituted 590,600 , which is by 5,000 more than as of January 1, 2014.

By the results of the data countrywide, there was passed the Federal Law dated July 23, 2013, No. 237FZ"On Amending Article 22 of the federal Law "Concerning Mandatory Pension Insurance in the Russian Federation" -Articles 14 and 16 of the Federal Law "On Insurance Premiums to the Pension Fund, Social Insurance Fund, Mandatory Medical Insurance Fund and Territorial Funds of Obligatory Insurance of the Russian Federation", according to which individual entrepreneurs with yearly income up to RUB 300,000 are to get back the fixed fee, calculated on the basis of 1 minimum monthly wage.

State forecasting of socio-economic development of business is a system of scientifically substantiated ideas of directions of socio-economic development of activities of small and medium business, based on the laws of market economy. Forecasting is a precondition for planning.

Planning is activity of the state through its authorities and subjects of economic activities for development of plans, which are a succession of actions, coordinated as to goals and resources and aimed for achievement of certain final result. Types of planning: 
- Directive planning supposes obligation and responsibility of corresponding subjects for fulfillment of the planned indicators

- Indicative planning supposes setting certain indicators for the purpose of achieving proportion and balance of development of economy and its specific parts

The following measures were fulfilled for preparation of the forecast of development of the sphere of small and medium business in Russia:

- Critical analysis of the data of the "Forecast of socio-economic development of the Russian Federation for 2014 and planned period of 2015 and 2016" was conducted

- Survey of experts in the sphere of state policy of development of small and medium business in Russia was conducted

- The expert round table was held

According to the "Forecast of long-term socioeconomic development of the Russian Federation until 2030", the main vectors of state policy as to development of small and medium business in long-term are:

- Decrease of the level of financial load on business subjects from excessive administrative barriers

- Expansion of measures of property support for business subjects (privatization of state property, increase of the quantity of objects of infrastructure of business support)

- Simplification and cheapening of access to objects of communal infrastructure

- Perfection of labor law which regulates relations in the entrepreneurial sphere

The Ministry of economic development and trade of the Russian Federation, together with autonomous noncommercial organization "Agency for strategic initiatives for promotion of new projects" and business society form the National business initiative.

This initiative consists of "road maps" -plans of initial measures, aimed at the improvement of conditions for business activities in the most important and problematic spheres of state regulation.

At present, 12 "road maps" are confirmed:

- Increase of the quality of regulatory environment for business

- Optimization of procedures of registration of legal entities and individual entrepreneurs

- Development of competition and perfection of antimonopoly policy

- Increase of the quality of services in the sphere of state cadastral registration of real estate property, registration of rights and of deals with it
- Perfection of legal regulation of urban development and improvement of business climate in the sphere of building

- Increase of accessibility of energy infrastructure

- Support for access to the markets of foreign countries and support for export

- Perfection of customs administration

- Expansion of access of business subjects to purchases of infrastructural monopolies and companies with state share

- Perfection of evaluating activities

- Perfection of tax administration

- Perfection of procedures of bankruptcy

Depending on targeted and indicative indicators of "road maps", the bodies of executive power of the RF conduct monitoring and fulfillment of projects' measures.

\section{Results}

Organizational forms of state regulation of business are measures of managerial (when necessary-directive) order, used within the limits set by the law and competent authorities for economy on the whole, its specific spheres, as well as types and subjects of economic activities (Cao et al., 2015).

Organizational forms of state regulation of business activities include state registration of business subjects, licensing, mandatory instructions, usage of standards and setting quotas (Yang et al., 2015).

The Federal Law dated May 4, 2011, No. 99-FZ "On licensing certain activities" determines the types of activities, the performance of which is possible only after obtaining the permit (license) from public authorities. License is a special permit for performance of specific type of activities with mandatory compliance with license requirements and conditions, issued by licensing body to legal entity or individual entrepreneur.

Licensing covers around 50 types of activities. The list of licensing bodies is set by the Government of the RF. The Decree of the Government of the Russian Federation dated November 21, 2011, No. 957 "Concerning the organization of licensing of certain types of activity" sets the list of federal bodies of executive power which conduct the licensing of particular types of activities.

The Federal Law dated December 7, 2002, No. 184FZ"Concerning technical regulation" determines that certification is a form of confirmation of objects' compliance with requirements of technical regulations, standards, sets of rules, or terms of agreements, performed by certifying body.

On January 1, 2014, the Federal Law dated April 5, 2013, No. 44-FZ"Concerning contract system in the sphere of central and local government procurement of 
goods, works and services" went into effect. Article 30 of this law sets the obligation of customer to perform purchases of goods, works and services from subjects of small business and socially oriented non-profit organizations to the extent not less than $15 \%$ of the scheduled plan of purchases.

Legal forms of state regulation of economy include business contract and sanctions applied to economic subjects-transgressors in economic relations. Protection of the subjects of business activities, as a form of state regulation, is characterized by specific measures for restoration or acknowledgment of violated or disputed rights of these subjects.

Forms of protections are divided into judicial and extrajudicial. Judicial forms of protection are used in strict compliance with procedural legislation. Protection of rights and legal interests of the subjects of small and medium business, as it is, conducted through resolution of economic disputes, i.e., specific in their legal nature, requires rather narrow specialization and high professionalism. This task could be solved by specialized and professional formal legal institutes.

Rights of legal entities and individual entrepreneurs during inspection are set by the Federal Law dated December 26, 2008, No. 294-FZ“'On the protection of legal entities' and individual entrepreneurs' rights in the course of state control (supervision) and municipal control". The Federal Law dated May 7, 2013, No. 78FZ"Concerning business rights commissioners in the Russian Federation" determines: Legal situation, main tasks and competence of the RF Presidential Commissioner for the rights of the Business People, as well as commissioners for the rights of business people in the subjects of the Russian Federation.

In 2010, the Ministry of economic development and trade of the Russian Federation started the implementation of a new tool in the system of decision making, aimed at reduction of administrative pressure on business, creation of transparent mechanisms of making regulating decisions, improvement of investment and entrepreneurial climate-the System for Evaluation of Regulating Influence (SERI).

The goals of the SERI are the following:

- Determination and evaluation of possible positive and negative consequences of implementation of statutory instruments on the basis of analysis of the problem, aim of its regulation and possible means of solution

- Determination of provisions which introduce excessive obligations and limitations for subjects of entrepreneurial and investment activities or stimulate their implementation

- Determination of provisions which facilitate the emergence of unsubstantiated expenses of subjects of business and investments activities, as well as budgets of all level of budget system of the Russian Federation

According to Article 7 of the Federal Law "Concerning development of business in the Russian Federation" (hereafter-the Law concerning development of business), for the purpose of implementation of state policy in the sphere of development of small and medium business in the Russian Federation, the federal laws and other statutory instruments of the Russian Federation may set the following measures of state support of subjects of small and medium business:

- Special tax regimes, simplified rules of tax accounting, simplified forms of tax declarations for particular taxes and charges for small enterprises

- Simplified forms of accounting, including simplified accounting (financial) reports and simplified forms of cash payments for small enterprises

- Simplified way of small and medium enterprises' subjects' preparing statistical reports

- Privileged way of payments for state and municipal property, privatized by subjects of small and medium business

- Peculiarities of participation of the subjects of small business as suppliers (performers, contractors) in purchases of goods, works and services for state and municipal needs

- Measures for provision of rights and legal interests of the subjects of small and medium business during state control (supervision)

- Measures for provision of financial support of the subjects of small and medium business

- Measures for development of infrastructure of support for subjects of small and medium business

- Other measures, aimed at provision of implementation of goals and principles of the Law concerning development of business

In this article, a cluster is understood as a comprehensive system of new products and technologies, interconnected and concentrated on certain period of time and in certain economic environment. During creation of cluster, the main aim is receipt of synergetic effect from constant technological renewal of manufactured products. As a rule, the core of a cluster is one company or association of companies which, through vertical and horizontal connections, cooperate with other organizations of a cluster. Apart from cluster core, there are also supplementary organizations which provide necessary technologies, information, financial resources and infrastructure for successful functioning.

Thus, cluster is a combination of various organizations (industrial companies, higher educational 
establishments, technological parks and business incubators, R\&D centers and laboratories, bank and nonbank credit companies, investment and innovational companies, venture funds, business angels, public authorities, public organizations, etc.), allowing using advantages of intra-company hierarchy and market mechanism, which allows reacting and distributing new knowledge, scientific inventions and innovations.

In other words, cluster is a combination of legally independent from one another sectorial and intersectorial business structures which function on a certain territory, but are connected by internal cooperation ties with each other and inter-regional infrastructure of provision of successful entrepreneurial activities on specific territory of their location, with possibility for working at markets of any level within country and abroad.

The difference of cluster from other forms of economic associations consists in the fact that cluster companies do not fully merge but create a mechanism of cooperation, allowing them preserving the status of legal entity and cooperating with other enterprises which create cluster-both within and beyond it.

Therefore, cluster is an innovational and organizational form of state regulation of business. Within this form, a complex combination of competition and cooperation is formed-especially, in innovational processes. Cooperation within cluster is conducted through vertical (chains of purchases and sales) and horizontal connections (additional products and services, use of similar specialized processes, technologies, or institutions). It is the interconnections within cluster and its member's capability to effectively use internal and mobilize external resources that competitiveness of the whole cluster depends on (Cooke, 2012).

Clusters become a peculiar "platform" in which constant cooperation of financial and intellectual capital is conducted (Cortright, 2013). In effectively functioning clusters, the innovational process is quickened and cluster members develop such advantages as commitment to innovations, rationalization of business, outrunning growth of productivity, etc.

Cluster includes the whole innovational chain, from generation of scientific knowledge and formation on their basis of business ideas to implementation of market products on traditional or new sales markets (de Miguel Molina and Garrigós, 2011). Structural elements of regional cluster are the following varieties of organizations (Desrochers, 2014):

- Scientific organizations of federal jurisdiction which perform research activities according to national priorities of scientific and technical development

- Scientific organizations of regional jurisdiction, the activities of which is aimed at solving tasks of scientific and technical development of this region
- Higher educational establishments which prepare highly qualified staff for region's economy

- Enterprises which make innovations

- Small innovational enterprises

- Organizations of innovational infrastructure

- Regulatory bodies of regional scientific and technical complex

Scientific organizations are a basis of scientific and technological complexes and research groups of different sectors of science create the environment which generates knowledge. Infrastructural provision of innovational process at the modern stage of development is a dominating component during creation of regional scientific and technical complexes, as activity of usage of infrastructural elements allows receiving synergetic effect.

Structure of regional scientific and technological clusters includes the following elements: subjects of scientific and technological activities which directly conduct the research; subjects of scientific and technological activities which conduct research and development and implementation of their results in economic turnover; and elements of management which conduct targeted influence on elements of scientific and technological complex for the purpose of their progressive development.

In our opinion, the approach to regional development, based on clusters, should be applied in Russia. Effective restructuring of large industrial enterprises and territorial and industrial complexes requires close cooperation between large, middle and small business and constructive cooperation with universities and R\&D organizations with absolute support from federal and regional bodies of state power. Here, the application of cluster approach provides necessary tools and methodology which allow achieving expanded development of small innovational business.

Thus, as a result of the conducted research, the following advantages of innovational clusters from the point of view of development of small innovational business were revealed:

- Cluster includes the whole innovational chain from generation of scientific knowledge and formation of business ideas on their basis to realization of commercial output in traditional or new sales markets

- Cluster companies do not fully merge, but, with the help from regional authorities, create a mechanism of cooperation which allows them to preserve a status of legal entity and to keep cooperating with other cluster enterprises-both within and beyond it

- Clusters are a basic condition for creation of mechanisms of development of innovational business and innovations as such-in regions and in the country on the whole 
- Clusters quicken the development of business, facilitate quicker search for resources, knowledge, technologies and ideas which can be implemented into development of business

- Clusters perform stimulating function from the point of view of innovational development, as they facilitate active informational exchange between the members

- Clusters increase labor efficiency, as companies have better access to highly-qualified staff through regional labor market and cooperation with educational establishments

- Clusters are centers for development of cooperation and competition which facilitate the growth of companies' efficiency, determine the path of innovations development and stimulate creation of new business directions

\section{Conclusion}

Thus, as a result of the conducted research, the offered hypothesis was proved and it may be concluded that cluster is an innovational organizational form of state regulation of entrepreneurship. A peculiar feature of cluster consists in the fact the clusters do not fully merge, but create a mechanism of cooperation which allows them to preserve a status of legal entity and to keep cooperating with other cluster enterprises, beyond it as well.

Cooperation within cluster is conducted through vertical (chains of purchases and sales) and horizontal connections (additional items and services, use of specialized processes, technologies, or institutes). It is the cooperation within cluster, its members' capability to effectively use internal and mobilize external resources that competitiveness of the whole cluster depends on.

Clusters become a peculiar "platform" in which constant cooperation of financial and intellectual capital is conducted. In effectively functioning clusters, the innovational process is quickened and cluster members develop such advantages as commitment to innovations, rationalization of business, outrunning growth of productivity, etc.

Cluster includes the whole innovational chain, from generation of scientific knowledge and formation on their basis of business ideas to implementation of market products on traditional or new sales markets.

\section{Funding Information}

The authors have no support or funding to report.

\section{Author's Contributions}

All authors equally contributed in this work.

\section{Ethics}

This article is original and contains unpublished material. The corresponding author confirms that all of the other authors have read and approved the manuscript and no ethical issues involved.

\section{References}

Popkova, E.G. and V.I. Tinyakova, 2013a. New quality of economic growth at the present stage of development of the world economy. World Applied Sci. J., 5: 617-622.

DOI: 10.5829/idosi.wasj.2013.24.05.13214

Popkova, E.G. and V.I. Tinyakova, 2013b. Drivers and contradictions of formation of new quality of economic growth. Middle-East J. Sci. Res., 11: 1635-1640.

DOI: 10.5829/idosi.mejsr.2013.15.11.11656

Popkova, E.G., S.S. Morkovina, E.V. Patsyuk, E.A. Panyavina and E.V. Popov, 2013. Marketing strategy of overcoming of lag in development of economic systems. World Applied Sci. J., 5: 591-595. DOI: 10.5829/idosi.wasj.2013.26.05.13489

Cao, B., F. Glover and C. Rego, 2015. A tabu search algorithm for cohesive clustering problems. J. Heurist., 12: 21-24. DOI: 10.1007/s10732-015-9285-2

Yang, Z., P. Hao and J. Cai, 2015. Economic clusters: A bridge between economic and spatial policies in the case of Beijing. Cities, 42: 171-185. DOI: $10.1016 /$ j.cities.2014.06.005

Cooke, P., 2012. From clusters to platform policies in regional development. Eur. Planning Stud., 20: 1415-1424. DOI: 10.1080/09654313.2012.680741

Cortright, J., 2013. Making sense of clusters: Regional competitiveness and economic development. Brookings Institution, Washington, DC.

de Miguel Molina, M. and J.A. Garrigós, 2011. The innovative regional environment and the dynamics of its clusters. Eur. Planning Stud., 19: 1713-1733. DOI: 10.1080/09654313.2011.614383

Desrochers, P., 2014. Cluster-based economic strategy, facilitation policy and the market process. Rev. Austrian Econom., 17: 233-245. DOI: 10.1023/B:RAEC.0000026833.26220.2d 